\title{
Non-contrast enhanced, EKG-triggered, navigator MR angiography of the thoracic aorta and proximal pulmonary arteries: initial evaluation of using an abdominal compression band to reduce acquisition times
}

\author{
Emer Sonnex ${ }^{*}$, Indrajeet Das, Richard Coulden \\ From 17th Annual SCMR Scientific Sessions \\ New Orleans, LA, USA. 16-19 January 2014
}

\section{Background}

Non-contrast enhanced, EKG-triggered, navigator 3DSSFP magnetic resonance angiography (NCE-MRA) is a robust technique but suffers from long scan acquisition times. Depending on heart and respiratory rates, acquisition times can still be prohibitively long. We describe the use of an abdominal compression band to reduce respiratory motion and image acquisition time with no sacrifice of image quality.

\section{Methods}

Ethics committee approval and informed consent were obtained. 20 normal volunteers (mean age: 39$)$ underwent two NCE-MRA examinations. Both examinations were performed free-breathing, one with an abdominal compression band (band) and one without (no-band). Both examinations were performed on the same $1.5 \mathrm{~T}$ Aera (Siemens Medical Solutions) with identical scanning parameters within 10 minutes of each other. Each examination duration was recorded. All angiographic data sets were anonymized. Data sets were reviewed in random order by three cardiothoracic radiologists on a single workstation. Motion artifact and overall quality were assessed semi-quantitatively on a scale of $1-4$ (excellent/no artifact - 1; good/minor artifact/noise - 2; moderate/some noise/artifact - 3; poor/limited diagnostic quality - 4).

\section{Results}

NCE-MRA was completed successfully with and without an abdominal compression band in all volunteers $(40$ data sets). There was no difference in global image quality or motion artifact at the aortic root between 'band' and 'no-band' examinations (mean image quality 1.31 and 1.51; mean aortic root artifact 1.25 and 1.44 respectively). No studies in either group were rated moderate or poor. None of the observers could reliably distinguish between 'band' or 'no-band' examinations. Scan times between the 2 groups were, however, significantly different. Scan times ranged from 4.5 - 9.1 minutes (mean 6.7; SD 1.14) in the 'no-band' group and 3.3 to 8.9 minutes (mean 5.0; SD 1.3) in the 'band' group. Mean reduction in acquisition time between the two groups was 1.7 mins or $25 \%$ of the standard technique $(\mathrm{p}=0.0025)$. Only 1 data acquisition time increased with the abdominal band.

\section{Conclusions}

Using an abdominal compression band in non-contrast enhanced, EKG-triggered, navigator 3D-SSFP MRA significantly reduces image acquisition time $(25 \%)$ without sacrificing image quality. This technique has only been used in volunteers to date. Further study will be needed to see if this benefit is maintained in patients.

\section{Funding}

None. 


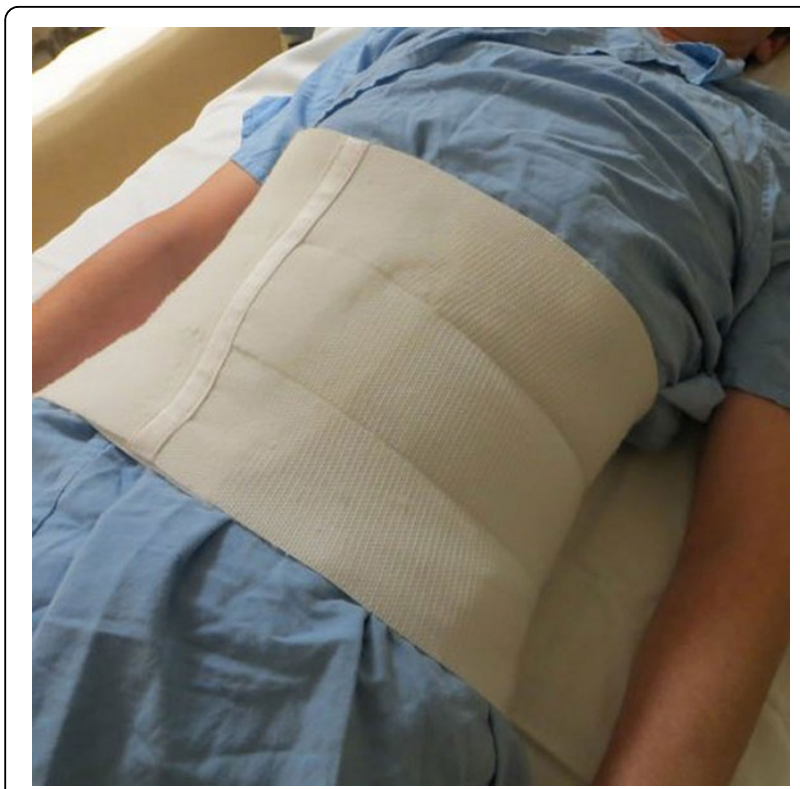

Figure 1 Broad, elasticated abdominal belt applied tightly at end expiration.

Published: 16 January 2014

doi:10.1186/1532-429X-16-S1-P375

Cite this article as: Sonnex et al:: Non-contrast enhanced, EKG-triggered, navigator MR angiography of the thoracic aorta and proximal pulmonary arteries: initial evaluation of using an abdominal

compression band to reduce acquisition times. Journal of Cardiovascular Magnetic Resonance 2014 16(Suppl 1):P375.

\section{Submit your next manuscript to BioMed Central} and take full advantage of:

- Convenient online submission

- Thorough peer review

- No space constraints or color figure charges

- Immediate publication on acceptance

- Inclusion in PubMed, CAS, Scopus and Google Scholar

- Research which is freely available for redistribution

Submit your manuscript at www.biomedcentral.com/submit
C Biomed Central 